\title{
Phased evacuation algorithm for high-rise buildings
}

\author{
Marina Gravit ${ }^{1}$, Ivan $_{\text {Dmitriev }}{ }^{1 *}$, and Kirill Kuzenkov ${ }^{1}$ \\ ${ }^{1}$ Peter the Great St. Petersburg Polytechnic University, 29 Politechnicheskaya St., St. Petersburg, \\ 195251, Russian Fedeation
}

\begin{abstract}
The article explores a new phased evacuation algorithm for high-rise buildings and structures. The necessity of using this evacuation type is justified by reducing of the human flow density, which minimizes the people injury risks and the crowd formation during the movement process. This type of evacuation prevents the appearance of clusters in local narrowing places (the floor entrance), as well as on stairway. The calculation model is made in Pathfinder PC. The scheme of organizing a phased evacuation is based on the separation of the evacuating people flows and the prevention of their crossing. The design scheme is given for the twenty-story section of a high-rise building. A detailed instruction describes the process of dividing a section into stages and determining the sequence of evacuation floors. The time delays table is calculated for each floor of the simulated twenty-storey section.
\end{abstract}

\section{Introduction}

At present, there is a world trend in the high-rise construction development. Such buildings are subject to special requirements for ensuring fire safety, especially in terms of the construction material quality control and the organization of effective evacuation measures [1-4]. Particular attention is also paid to space-planning solutions [5], the flame effects on the structures operation [6-9] and the need for additional fire protection [10-15]. The evacuation process analysis from high-rise buildings considers the space of streams crossing between descending people the stairs and people leaving the floor as one of the most problematic areas [16]. These places of a continuous density increase of the human cluster (7-8 people per $\mathrm{m}^{2}$ ) form sharply high chances of injury and compression asphyxia during the crush.

There are several models for organizing the evacuation process [17-19]. One of the most effective solutions is the organization of a phased pedestrian evacuation [20].

The algorithm is defined by the following concept:

1. Priority evacuation of the fire floor and several floors above it. Periodic evacuation of the nearest floors below the level of ignition;

\footnotetext{
* Corresponding author: i.i.dmitriev@ yandex.ru
} 
2. Consecutive evacuation of the remaining floors. First, organized order of people from the nearby floors above the fire to the top. Then system announces the evacuation of the lower floors;

3. The parameters of the movement of the human flow (the time of the people exit beginning from each floor (the signalling intervals) are calculated, the potential for the clusters formation on the staircase due to the merger of counter flows is excluded.

This typical algorithm is justified by the vertical spread of poisonous combustion products and smoke, which quickly spread through the ventilation system despite the security of the staircase-elevator units and the insulation of window openings [21, 21]. Also, with the fire of facade structures, the flame, first of all, will pass to the nearby upper and lower floors.

The phased evacuation does not necessarily lead to an evacuation acceleration [23]. This trend is especially evident when comparing the calculated evacuation time of a simultaneous and a phased evacuation algorithm. Nevertheless, when people move during a real fire, the actual time will be influenced not so much by the "calculated seconds of advantage", but by the possibility of non-stop and planned movement. At a rarefied density ( 3 people $/ \mathrm{m}^{2}$ ), the risk of injury is minimized, the panic onset and also the potential overlapping of the motion path by falling from the ladder [24, 25]. It should be specially noted that at this density the main causes of the most dangerous factors for health (asphyxiation and trampling) are practically removed. The movement characteristics of the human flow are described in the [26].

\section{Methods}

Calculations are carried out in the Pathfinder PC based on an individually-streamed motion algorithm [27, 28]. There is a high-rise multi-storey building in the model, which is divided into twenty-storey sections [29]. The evacuation time was calculated during the movement on the stairs. The calculations were carried out without taking into account the less mobile population. A unit of calculation time (time step) is 0.25 seconds.

There are main parameters of the calculated building:

- 100 people per floor (1 person per $\left.6 \mathrm{~m}^{2}\right)$;

- Two U-shaped stairs of type H3, a march of $1350 \mathrm{~mm}$;

- Every $20^{\text {th }}$ floor is technical. It is a fire-safe zone, which consist from a safe compartments complex [30-34].

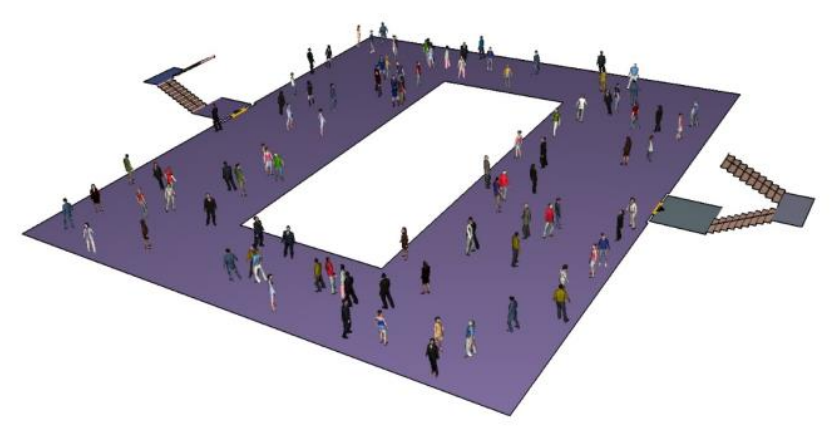

Fig. 1. The simulated building floor plan.

The phased evacuation model will be implemented according to the following scheme:

1. General application principle of the universal phased evacuation model.

1.1. The first stage (I - red zone). Evacuation of floors in the nearest fire zone.

1.1.1. n (floor with the seat of fire) - without delay; 
1.1.2. $\mathrm{n}+1$ (overlying floor) after a period which there will be no intersection of evacuating human flows from the upper and lower floors;

1.1.3. $\mathrm{n}+2$ in a step after $\mathrm{n}+1$;

1.1.4. $n-1$ starts moving after people from $n+2$ floor pass the level $n-1$. This is taken to eliminate the flow intersection;

1.1.5. $n+3$ is selected with the required delay to free the path for people from the $n-1$ level. At the same time, this period should be short as necessity to provide continuous evacuation;

1.1.6. $\mathrm{n}+4$ in a step after $\mathrm{n}+3$

1.1.7. $\mathrm{n}-2$ by analogy with $\mathrm{n}-1$ (subsection 1.1.4) after $\mathrm{n}+4$

1.1.8. $n+5, n+6, n-3$ and $n+7$ by analogy with the items above (subsection 1.1.2-1.1.5). Evacuation of the $n+7$ level should begin earlier than $n-3$ if we can provide single human flow.

1.2. The second stage (II - green zone). Consecutive linear evacuation of floors above the seat of fire. It begins with the level $n+8$. The time interval is chosen so that the human flow is continuous. People from floors do not break into the general flow, which is moving inside the staircase.

1.3. The third stage (III - blue zone). Evacuation of all remaining floors from $n-4$ to below. In this case, the priority of the evacuation is the reverse of 1.2. Each floor is waiting for the moment when the floor above it will come down below the current floor, so as not to create intersections.

1.4. Free evacuation can be allowed without interfering with the basic sequence of the algorithm from the lower floors in the first stage.

2. To develop a phased evacuation scheme for the seat of fire location on a particular floor, it is necessary to close part of the schedule with floors that are not present in a specific situation, or to continue the diagram if necessary. The coloured cells, which is obtained in the corrected diagram, are used to determine the evacuation sequence.

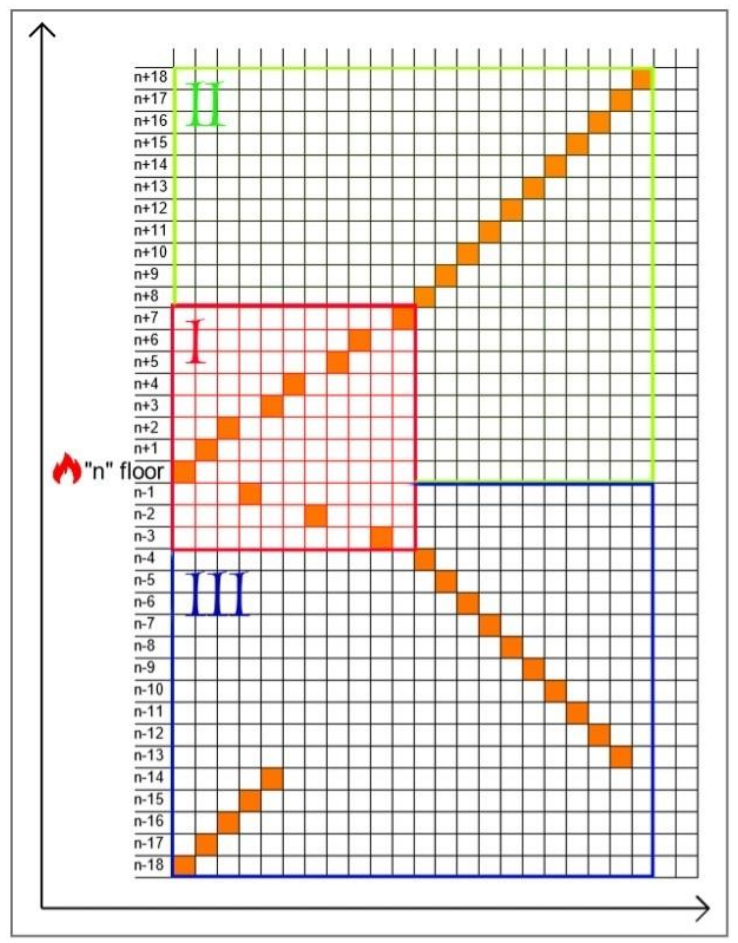

Fig. 2. Scheme of phased evacuation organization. 


\section{Results and Discussion}

In the simulations of synchronous evacuation, density clusters $7-8$ people $/ \mathrm{m}^{2}$ appear. This completely agrees with the theoretical calculations.
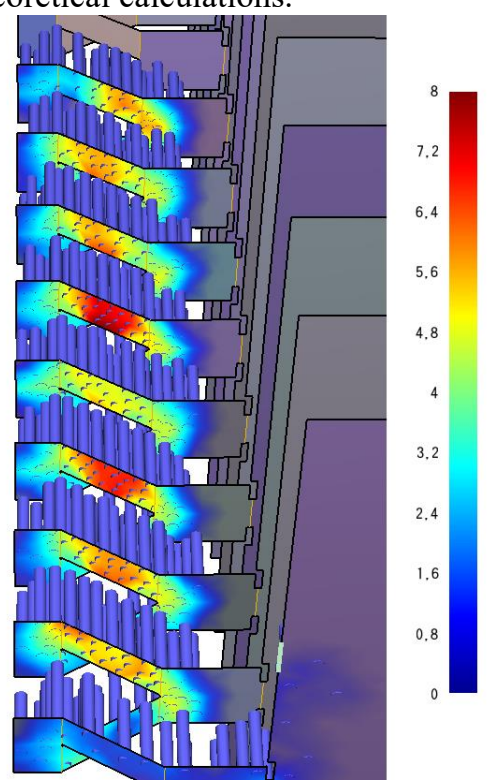

Fig. 3. Human flow density with the simultaneous evacuation.

We calculate three boundary cases of the location of the fire seat.

a) Fire on the 1st floor;

Let us consider a part of the phased evacuation scheme (Fig. 4).

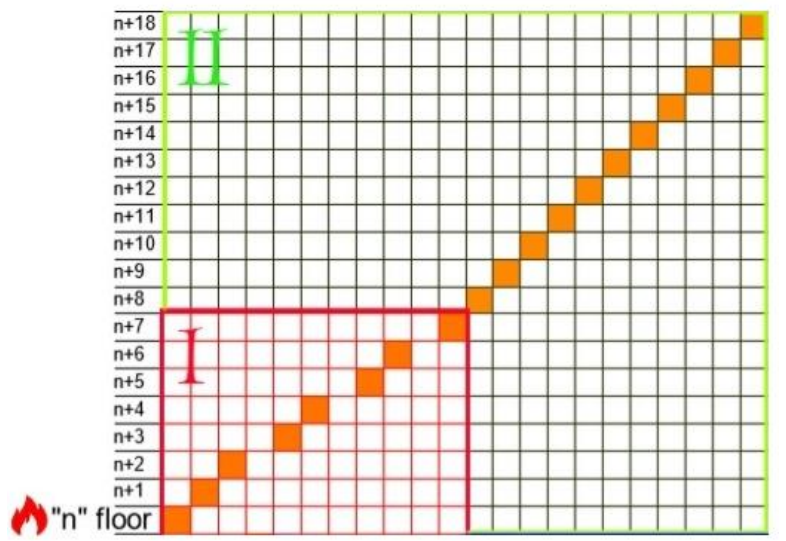

Fig. 4. Part of the phased evacuation scheme for the case of a fire on the 1 st floor.

The evacuation process follows the algorithm of the methods in subsection 1.2.

We calculate from simulated model that from the 1st to the 10th floor, the step is 20 seconds. The flow density begin to increase to 4.5 (Fig. 5a) starting from the 10th floor. The start-up interval increases to 30 seconds from 10 to 15 floors to thin out the flow. We take a time step equal to 20 seconds again in the following floors (Fig. $5 b$ ). 

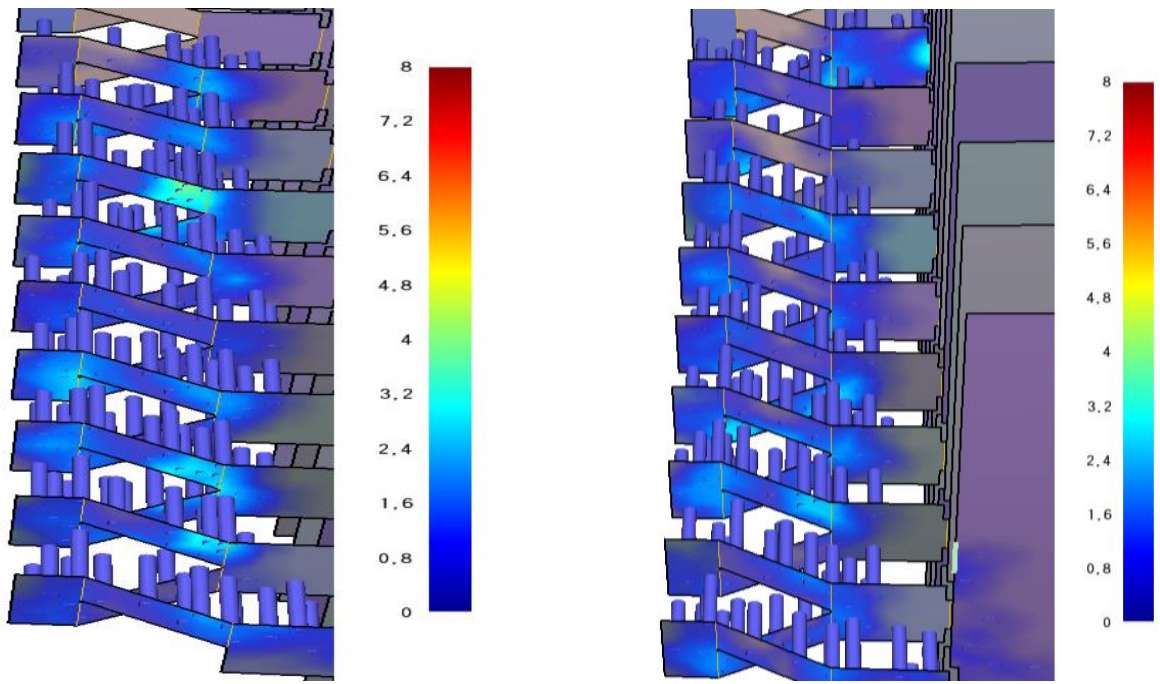

Fig. 5. Isopole of the human flow density, 1-10 floor.
a) with a delay of 20 seconds per floor.
b) with an additional delay on the $10-15$ th floor in 30 seconds.

b) Fire on the $19^{\text {th }}$ (last) floor;

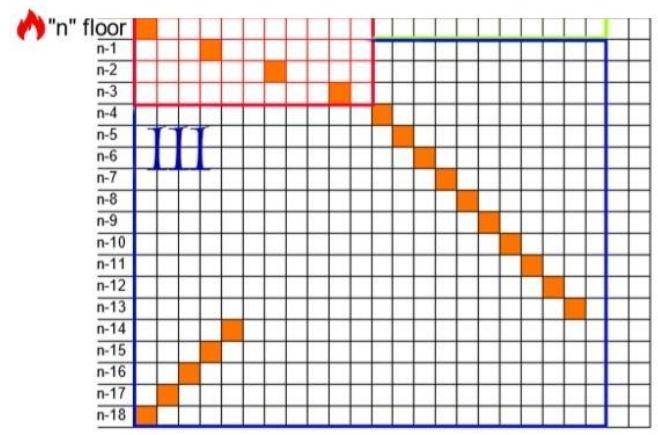

Fig. 6. Part of the phased evacuation scheme for the case of a fire on the 19th floor.

The evacuation process is according to the algorithm of the methods subsection 1.3.

We calculate from simulated model that the time step is 50 seconds. There is a period after evacuation beginning from the 19th floor for which the 6 low floors with a time step of 20 can be evacuated without hindrance (subsection a).

c) Fire on the 10th (middle) floor;

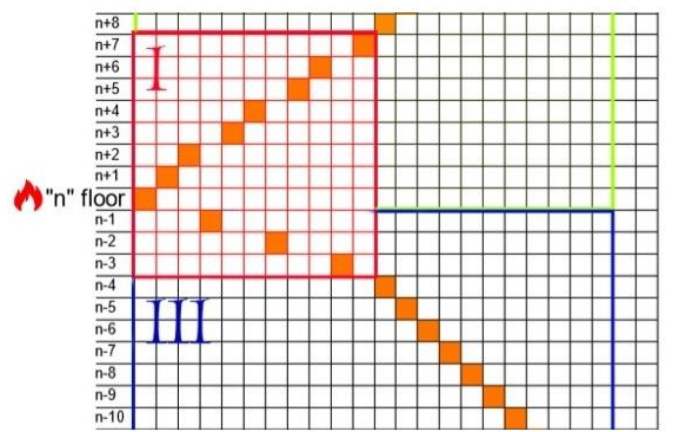

Fig. 7. Part of the phased evacuation scheme for the case of a fire on the 10th floor. 
According to the Methods subsection 1.1 (1st stage), we begin evacuation from the floors above the seat of fire. We take a time interval of 20 seconds using the calculations of Results section "a".

The estimated time-step values for floors $n-1, n-2$ and $n-3$ are 120, 260, 440 respectively. The values inside the first stage square are valid for all other cases of the possible fire location. The estimation time delay of the fire seat on the floors close to the stage boundary, it is necessary to take into account the truncation of the first stage zone (there may be no stage of the evacuation beginning from the level $n-3$ or $n-2$. This leads to uncertainty in the moment of the second stage beginning (subsection 1.2) It continues in the upper right quarter of the table, taking into account the presence / absence of the $n-3, n-2$ and $n-1$ levels in the first stage.

The received values of the underlying sector is filled in cells in 50 second increments, according to Results section "b". We compose a table of time delays for each floor of the consideration section based on the calculations "a-c". Values are obtained during the simulation.

\begin{tabular}{|c|c|c|c|c|c|c|c|c|c|c|c|c|c|c|c|c|c|c|c|}
\hline & 1 & 2 & 3 & 4 & 5 & 6 & 7 & 8 & 9 & 10 & 11 & 12 & 13 & 14 & 15 & 16 & 17 & 18 & 19 \\
\hline 1 & 0 & 20 & 40 & 60 & 80 & 100 & 120 & 140 & 160 & 190 & 220 & 250 & 280 & 310 & 330 & 350 & 370 & 390 & 410 \\
\hline 2 & 0 & 0 & 20 & 40 & 60 & 80 & 100 & 120 & 140 & 160 & 190 & 220 & 250 & 280 & 310 & 330 & 350 & 370 & 390 \\
\hline 3 & 0 & 120 & 0 & 20 & 40 & 120 & 140 & 160 & 180 & 200 & 220 & 240 & 260 & 290 & 320 & 350 & 380 & 410 & 430 \\
\hline 4 & 0 & 260 & 120 & 0 & 20 & 40 & 120 & 140 & 240 & 260 & 280 & 300 & 320 & 340 & 360 & 380 & 410 & 440 & 470 \\
\hline 5 & 0 & 440 & 260 & 120 & 0 & 20 & 40 & 120 & 140 & 240 & 260 & 380 & 400 & 420 & 440 & 460 & 480 & 500 & 520 \\
\hline 6 & 0 & 0 & 440 & 260 & 120 & 0 & 20 & 40 & 120 & 140 & 240 & 260 & 380 & 400 & 420 & 440 & 460 & 480 & 500 \\
\hline 7 & 0 & 0 & 740 & 440 & 260 & 120 & 0 & 20 & 40 & 120 & 140 & 240 & 260 & 380 & 400 & 420 & 440 & 460 & 480 \\
\hline 8 & 0 & 0 & 750 & 700 & 440 & 260 & 120 & 0 & 20 & 40 & 120 & 140 & 240 & 260 & 380 & 400 & 420 & 440 & 460 \\
\hline 9 & 0 & 0 & 760 & 710 & 660 & 440 & 260 & 120 & 0 & 20 & 40 & 120 & 140 & 240 & 260 & 380 & 400 & 420 & 440 \\
\hline 10 & 0 & 0 & 20 & 720 & 670 & 620 & 440 & 260 & 120 & 0 & 20 & 40 & 120 & 140 & 240 & 260 & 380 & 400 & 420 \\
\hline 11 & 0 & 0 & 20 & 730 & 680 & 630 & 580 & 440 & 260 & 120 & 0 & 20 & 40 & 120 & 140 & 240 & 260 & 380 & 400 \\
\hline 12 & 0 & 0 & 20 & 730 & 680 & 630 & 580 & 540 & 440 & 260 & 120 & 0 & 20 & 40 & 120 & 140 & 240 & 260 & 380 \\
\hline 13 & 0 & 0 & 20 & 740 & 690 & 640 & 590 & 540 & 490 & 440 & 260 & 120 & 0 & 20 & 40 & 120 & 140 & 240 & 260 \\
\hline 14 & 0 & 0 & 20 & 40 & 700 & 650 & 600 & 550 & 500 & 450 & 400 & 260 & 120 & 0 & 20 & 40 & 120 & 140 & 240 \\
\hline 15 & 0 & 0 & 20 & 40 & 660 & 610 & 560 & 510 & 460 & 410 & 360 & 310 & 260 & 120 & 0 & 20 & 40 & 120 & 140 \\
\hline 16 & 0 & 0 & 20 & 40 & 670 & 620 & 570 & 520 & 470 & 420 & 370 & 320 & 270 & 220 & 120 & 0 & 20 & 40 & 120 \\
\hline 17 & 0 & 0 & 20 & 40 & 60 & 710 & 650 & 590 & 530 & 470 & 410 & 350 & 290 & 230 & 170 & 120 & 0 & 20 & 40 \\
\hline 18 & 0 & 0 & 20 & 40 & 60 & 630 & 580 & 530 & 480 & 430 & 380 & 330 & 280 & 230 & 180 & 130 & 80 & 0 & 20 \\
\hline 19 & 0 & 0 & 20 & 40 & 60 & 80 & 600 & 550 & 500 & 450 & 400 & 350 & 300 & 250 & 200 & 150 & 100 & 50 & 0 \\
\hline
\end{tabular}

\section{\begin{tabular}{|llllllll}
\hline 1 & 2 & 3 & 4 & 5 & 6 & 7 \\
\cline { 2 - 3 }
\end{tabular}}

Fig. 8. Table of time delays for each floor of the consideration section.

There is a delay for each floor within the line. The left column shows the floor where the seat of fire is located. The scheme is divided into 7 colour zones (1-7), corresponding to different stages and sub-stages of the evacuation process.

1 st stage of evacuation (1.1 Methods) includes colours under the number 1, 2, 3. Where:

1 (yellow) - the floor of the fire seat $\mathrm{n}$ (subsection 1.1.1 method);

2nd (brown) - floors above $n$, starting from $n+1$ to $n+7$ (in the general case) (subsection 1.1.2 of the methodology);

$3 \mathrm{~d}$ (green) - floors under $\mathrm{n}$ from $\mathrm{n}-1$ to $\mathrm{n}-3$ (in the general case) (subsection 1.1.4 of the methodology).

The alternation of $n-$ and $n+$ follows the instructions given in the Methods.

2 stage (1.2 Methods) is displayed in 4 colours (blue). Consecutive linear evacuation of floors above the fire.

$3 \mathrm{~d}$ stage (1.3 Methods) follows the last chronology and is shown by zone 5 and 6 (blue and red). It begins after the moment when people from previous stages pass below it. Evacuation occurs with the same step in accordance with subsection 1.3 of the previous instruction. In general, an important detail is the definition of the evacuation beginning the $3 \mathrm{~d}$ stage (red colour of the table). In the table above, it was found experimentally. 
4th stage (subsection 1.4 of the Methods) is described by 7 colours (beige). Optional people evacuation from the lower floors in the 1st stage, which does not intersect with the main flow, but allows to reduce the evacuation time.

Let's consider a concrete example of calculation:

The seat of fire is on the 9th floor (Figure 9).

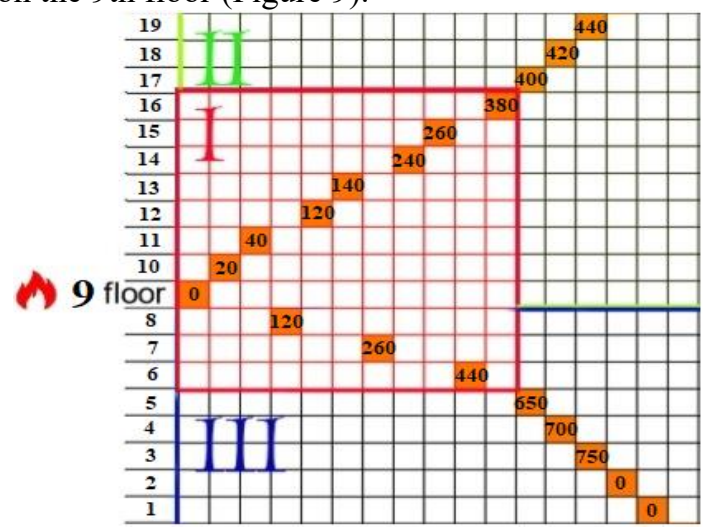

Fig. 9. Scheme of phased evacuation in case of fire on the 9th floor.

The estimated time delays for each floor are given in the 9th row of the table (Figure 8).

Instant start of the evacuation is announced on the floor with a fire (9th). At the same time, an optional evacuation of 1 st and 2 nd floors takes place. Then the two upper floors evacuation with an interval of 20 seconds is carried out. This time is enough for people from the lower floor to fully exit the stairwell, and accordingly there were no clusters from the flow meeting.

After 120 seconds the last person from the 11th floor will pass the 8th floor, and accordingly, the evacuation beginning of this floor is announced. Also the notification of the 12th floor is included. The delay between 11th and 12th floors was made for the possibility of 8th floor evacuation. For floors 13-16, the principle sequence is repeated.

After the beginning of the 16th floor movement, the evacuation of the upper floor is announced every 20 seconds.

After 650 seconds, the flow going from the 19th floor passes through the 5th floor, which serves as a signal for the beginning of its evacuation. The lower floors start moving every 50 seconds. 1 st and 2 nd floors managed to leave the building during the 1 st phase. The phased evacuation is completed.

There are 2 basic calculated values of the delay interval for two cases evacuation. The previous evacuation is located:

1. Below considered. This algorithm is typical for 2 nd stages. For this case, the delay time is 20 seconds.

2. Above considered. This algorithm is typical for $3 \mathrm{~d}$ stages. For this case, the delay time is 50 seconds.

\section{Conclusions}

In the article, we obtain the new organizing algorithm for phased evacuation from a highrise building and structure. The necessity of its application is substantiated, despite the higher value of the estimated time in comparison with the simultaneous evacuation. The values of time delays for each floor of the twenty-storey section are obtained. The possible example of this technique in the organization of evacuation for a particular floor is considered in detail. 


\section{References}

1. M. Gravit, I. Dmitriev, A. Ishkov, IOP Conf. Ser. Earth Env. Sc., 90, 012226 (2017). DOI:10.1088/1755-1315/90/1/012226.

2. T.A. Hezhev, A.V. Zhurtov, A.S. Tsipinov, S.V. Klyuev, Mag. Civ. Eng., 80, 4 (2018). DOI: 10.18720/MCE.80.16.

3. M. Al Ali, S.A. Isaev, N.I. Vatin, Mat. Phys. Mech., 26, 1 (2016).

4. I. Dmitriev, K. Kuzenkov, V. Kankhva, MATEC Web Conf., 193, 03030 (2018). DOI: 10.1051/matecconf/201819303030.

5. N.V. Gusakova, K.E. Filyushina, A.M. Gusakov, N.N. Minaev, Mag. Civ. Eng., 75, 7 (2017). DOI: 10.18720/MCE.75.8.

6. A.V. Alekseytsev, N.S. Kurchenko, Mag. Civ. Eng., 73(5), (2017). DOI: 10.18720/MCE.73.1.

7. I.A. Korotchenko, E.N. Ivanov, S.S. Manovitsky, V.A. Borisova, K.V. Semenov, Yu.G. Barabanshchikov, Mag. Civ. Eng., 69(1), (2017). DOI: 10.18720/MCE.69.5.

8. A.V. Bushmanova, N.V. Videnkov, K.V. Semenov, Yu.G. Barabanshchikov, A.V. Dernakova, V.K. Korovina, Mag. Civ. Eng., 71(3), (2017). DOI: 10.18720/MCE.71.6.

9. V.A. Rybakov, I.A. Ananeva, A.O. Rodicheva, O.T. Ogidan, Mag. Civ. Eng., 74(6), (2017). DOI: 10.18720/MCE.74.13.

10. T. Saknite, D. Serdjuks, V. Goremikins, L. Pakrastins, N. Vatin, Mag. Civ. Eng., 64(4), (2016). DOI: 10.5862/MCE.64.3.

11. M.R. Garifullin, A.V. Barabash, E.A. Naumova, O.V. Zhuvak, T. Jokinen, M. Heinisuo, Mag. Civ. Eng., 63, 3 (2016). DOI: 10.5862/MCE.63.4.

12. I.N. Priadko, V.P. Mushchanov, H. Bartolo, N.I. Vatin, I.N. Rudnieva, Mag. Civ. Eng., 65, 5 (2016). DOI: 10.5862/MCE.65.3.

13. V.D. Zakhmatov, M.V. Silnikov, M.V. Chernyshov, J. Ind. Poll. Cont., 32, 2 (2016).

14. M.V. Sil'nikov, M.V. Chernyshov, L.G. Gvozdeva, Tech. Phys., 61, 11 (2016). DOI: 10.1134/S1063784216110232.

15. P.V. Bulat, M.V. Chernyshev, Int. J. Env. Sc. Educ., 11, 11 (2016).

16. V.V. Kholshchevnikov, D.A. Samoshin, Hous. const., 8 (2008).

17. S. Kasereka, N. Kasoro, K. Kyamakya, E.-F. Doungmo Goufo, A. P. Chokki, M.V. Yengo, Proc. Comp. Sc., 130 (2018).

18. N.E. Groner, Fire Saf. J., 80 (2016). DOI: 10.1016/j.firesaf.2015.11.002. 
19. V.V. Yakovlev, M.V. Gravit, O.V. Nedryshkin, St. Petersburg State Polytechnic University Journal of Engineering Science and Technology, 1(190), 224-230 (2014)

20. T. Wada, A. Sekizawa, Bul. Japan Assoc. Fire Sc. Eng., 66(3), (2016). DOI: 10.11196/kasai.66.3_31.

21. M. Hung Nguyen, V. Ho Toung, J.D. Zucker, Simul. Model. Prac. Theory, 36 (2013). DOI: 10.1016/j.simpat.2013.04.001.

22. R. Dârmon, Proc. Manufact., 22 (2018).

23. A. Rahouti, S. Datoussaïd, T. Descamps, Inter. J. Dis. Resil. Built Env., 9(1), (2018). DOI: 10.1108/IJDRBE-10-2016-0039.

24. C.M. Harrie, Proc. Eng., 3 (2010).

25. O. F. Thompson, E. R. Galea, L.M. Hulse, Saf. Sc., 109 (2018).

26. V.V. Kholshchevnikov, D.A. Samoshin, A.P. Parfenenko, I.S. Kudrin, R.N. Istratov, I.R Belosokhov. Acad. St. Fire Serv. Ministry Emer. Meas. Russia (2015).

27. L. Bo, L. Yu-bao, W. Xiao-chuan, Proc. Eng., 52 (2013).

28. S.P. Leong, Fire Saf. Sc.-proc. Fourth Inter. Symp. (1994).

29. L. Al-Sharif, Lift Report, 43, 5 (2017)

30. A. Cowlard, A. Bittern, C. Abecassis-Empis, J. T., Proc. Eng., 62 (2013).

31. M.V. Gravit, O.V. Nedryshkin, O.T. Ogidan, Mag. Civ. Eng., 77(1), (2018). DOI: 10.18720/MCE.77.4.

32. O. Zybina, M. Gravit, Y. Stein, IOP Conf. Ser. Earth and Env. Sc., 90, 012227 (2017). DOI: 10.1088/1755-1315/90/1/012227.

33. M.V. Gravit, E.V. Golub, S.P. Antonov, Mag. Civ. Eng., 79(3), (2018). DOI: 10.18720/MCE.79.9.

34. A.E. Bolotin, D.B. Selyukin, Teoriya i Praktika Fizicheskoy Kultury (2015) 